\title{
Hypothesis: An acidosis-sparing ketogenic (ASK) diet to improve efficacy and reduce adverse effects in the treatment of refractory epilepsy
}

\author{
Alan W.C. Yuen ${ }^{1}$, Isabel A. Walcutt², Josemir W. Sander ${ }^{1,3 .}$ \\ ${ }^{1}$ NIHR University College London Hospitals Biomedical Research Centre, Department of \\ Clinical and Experimental Epilepsy, UCL Institute of Neurology, WC1N 3BG, London, UK \\ and Chalfont Centre for Epilepsy, Chalfont St Peter, UK; ${ }^{2}$ Eugene, Oregon, USA; ${ }^{3}$ Stichting \\ Epilepsie Instellingen Nederland (SEIN), Achterweg 5, 2103 SW Heemstede, the \\ Netherlands.
}

\section{ABSTRACT}

Diets that increase production of ketone bodies to provide alternative fuel for the brain are evolving from the classic ketogenic diet for epilepsy devised nearly a century ago. The classic ketogenic diet and its more recent variants all appear to have similar efficacy with approximately $50 \%$ of users showing a greater than $50 \%$ seizure reduction. They all require significant medical and dietetic support, and there are tolerability issues. A review suggests that low-grade chronic metabolic acidosis associated with ketosis is likely to be an important contributor to the short term and long term adverse effects of ketogenic diets. Recent studies, particularly with the characterization of the acid sensing ion channels, suggest that chronic metabolic acidosis may increase the propensity for seizures. It is also known that low-grade chronic metabolic acidosis has a broad range of negative health effects and an increased risk of early mortality in the general population. The modified ketogenic dietary treatment we propose is formulated to limit ketosis by measures that include monitoring protein intake and maximizing consumption of alkaline mineral-rich, low carbohydrate green vegetables. We hypothesize that this acidosis-sparing ketogenic diet is expected to be associated with less adverse effects and improved efficacy. A case history of life-long intractable epilepsy shows this diet to be a successful long-term strategy but, clearly, clinical studies are needed.

Keywords: low-grade chronic metabolic acidosis; ketones; ASIC; mitochondria; inflammation

Correspondence to Dr. Alan Yuen

Address: Chalfont Centre for Epilepsy, Chesham Lane, Chalfont St Peter, Bucks, SL9 ORJ, UK.

Telephone: +441494601348

Fax: +44 1494874136

Email: alan@yuen.co.uk 


\section{Introduction}

The use of the ketogenic diet (KD) as an epilepsy therapy started around the 1920's. It was developed to mimic the metabolic changes of starvation. The classic KD was generally initiated with a 24 - 48 hour fast, fluids were limited and total calories were typically restricted to $75 \%$ of the recommended dietary allowance (RDA) with $87 \%-90 \%$ of the person's caloric intake derived from fat, based on the classical 3:1-4:1 ratio of fat to protein plus carbohydrate [1]. KD was widely used in the 1920's and 1930's but its use declined with the advent of new antiepileptic drugs (AEDs) [2]. The last 25 years has witnessed the introduction of over 10 new antiepileptic drugs (AEDs) in the UK. One study, however, showed that there has been only a small improvement in the prognosis of epilepsy with the proportion of people achieving seizure freedom increasing from 64\% when analyzed in 1999 to $68 \%$ when analyzed in 2008 [3]. Despite the introduction of these new drugs, over $30 \%$ of people with epilepsy continue to have seizures. Over this same period and particularly since 2000 , there has been a marked resurgence in the use of the KD [2]. This has led to the development of less restrictive variants such as the Medium Chain Triglyceride Diet (MCT), which is $\sim 70 \%$ calories intake from fat, the Modified Atkins Diet (MAD), which is $\sim 60 \%$ calories from fat, and the Low Glycemic Index Treatment (LGIT), which is also 60\% calories from fat. All the variants appear to have efficacy comparable to the classic KD and they all comprise at least $\sim 60 \%$ calories from fat.

Classic KD, the MAD and the MCT diet generally produce hyperketonemia (2- $6 \mathrm{mM} / \mathrm{L}$ of beta hydroxybutyrate (BHB)) and a low-grade metabolic acidotic state. Low-grade chronic metabolic acidosis can be produced by increased consumption or production of organic acids [4], and in KDs, it mainly results from the generation of acidic ketone bodies. This generally produces a high anion gap, and bicarbonate levels may also be low. A number of studies have shown the association of KDs with metabolic acidosis [5-7].

Studies undertaken so far have not been able to demonstrate consistently a correlation between the extent of hyperketonemia and clinical efficacy. If the extent of hyperketonemia is not the critical factor for efficacy, might a diet not targeting high concentrations of BHB and thereby avoiding metabolic acidosis be more efficacious and be better tolerated? Here we provide the rationale for avoiding acidosis in dietary treatments. We describe the main principles in formulating an acidosis-sparing KD, and briefly summarize other elements of such a diet. 


\section{Acidosis-related adverse effects of ketogenic diet}

The human body has a number of mechanisms to maintain its $\mathrm{pH}$ balance, suggesting that deviations such as acidosis may have negative effects. The acidosis associated with the KD is thought to be complicated by a number of adverse events. Acutely, acidosis may be the cause or contribute to the reports of gastrointestinal disturbances, such as nausea, vomiting, diarrhea and constipation. In one study, 39\% of 129 people on KD reported these symptoms in the first 4 weeks of starting KD [8]. A possible mechanism for these adverse effects has been recently proposed, suggesting metabolic acidosis leads to acidification of the normally alkaline pancreatic juice and biliary secretion. This leads to impaired digestion in the small bowel. The poorly digested food accumulates in the small intestine where it is fermented by bacteria and yeast, producing large quantities of gas and toxic substances which can cause all the upper and lower gastrointestinal symptoms often reported in people on the KD [9].

Chronically, acidosis is thought to be the cause of a number of adverse events such as nephrolithiasis, osteopenia, fractures, growth retardation and cardiac effects. Nephrolithiasis is a significant adverse event associated with KD. In a US series of children on the KD, 11 $(10.5 \%)$ of those not given Polycitra K developed renal stones, compared to only $1(0.9 \%)$ out of 106 children given Polycitra K routinely at the start of KD treatment. Polycitra K treatment resulted in less acidic urine (mean $\mathrm{pH}: 6.8$ vs $6.2 ; \mathrm{P}=.002)$ [10].

Osteopenia resulting from the KD was first reported in 1979 in a study comparing 5 children on KD with 18 children taking AEDs and 15 healthy controls. The subjects on KD showed decreased serum 25-hydroxyvitamin D, calcium concentrations and decreased bone mass [11]. A recent study looked at 25 children with intractable epilepsy and found that their initial bone mineral status was poor compared to healthy children. After 15 months on KD their bone mineral content declined sharply [12]. The negative impact of acidosis on bone has long been known but was thought to result from passive, physicochemical dissolution of bone mineral content, but it has been shown that bone resorption by cultured osteoclasts is stimulated directly by acid. Acidosis also exerts a powerful inhibitory effect on the mineralization of bone matrix by cultured osteoblasts [13]. The effect of diet-induced acidosis leading to lower bone mineral densities also occurs in the general population. The factors in the modern Western diet resulting in metabolic acidosis have been described $[4,14]$. A study that had recruited 9724 people from the general population also suggests that metabolic acidosis, as evidenced by low bicarbonate concentrations, is associated with decreased bone mineral density - there was a significant linear trend across all quartiles of bicarbonate concentrations for lower bicarbonate concentrations to be associated with lower lumbar bone mineral densities [15].

In the longer term, the effect of acidosis on bone can lead to fractures. In a retrospective review of medical records, 6 of the 28 children who were treated with KD for $6-12$ years had fractures while on the diet and 4 of them had multiple fractures. The fractures occurred between 0.5 and 8 years after initiation of the diet [16].

A number of studies have shown that linear growth rate is also affected in children on KD $[12,17,18]$. It has been suggested that this is related to acidosis [12]. An observation that supports this suggestion is that the linear growth retardation seen in both proximal and distal renal tubular acidosis can be improved by correcting the acidosis [19].

It is known that metabolic acidosis in people with chronic renal failure can lead to muscle wasting and correction of the acidosis can mitigate the muscle loss [20]. This effect of 
acidosis on muscle may contribute to the diminished weight gain observed in people on KD. In a study of 129 people on KD, 73 continued on the diet for $>12$ months. Forty-seven $(65 \%)$ showed a decrease in weight percentile [8]. Other studies show similar effects of KD on body weight $[16,17]$.

The metabolic acidosis observed with KD may also have cardiac consequences. A study of 20 children on KD showed a significant correlation between prolonged QTc in the ECG (a marker for risk of arrhythmia) and both low serum bicarbonate and high BHB. Three of the children had evidence of cardiac chamber enlargement. The cardiomyopathy in one child resolved on discontinuing the diet [21].

\section{Rationale for limiting systemic acidosis}

The adverse effects described so far are likely to be reduced by limiting metabolic acidosis, and probably provide sufficient reasons to reduce KD-induced acidosis. Recent studies are elucidating the role of $\mathrm{pH}$ in neuronal function and suggest the potential for an acidic environment to increase seizure risk. Hence, there is growing body of evidence showing that limiting acidosis may potentially improve seizure control.

A receptor for $\mathrm{H}+$ that activated $\mathrm{Na}+$ current in mammalian neurons was first described in 1981 [22]. It was not until 1997 that a channel from the rat brain activated by $\mathrm{H}+$ and carrying an excitatory $\mathrm{Na}+$ current, was cloned [23]. This channel, ASIC1a, is now included in the family of $\mathrm{H}+$ gated ionic channels. Considerable progress has been made in further characterization of ASICs and in understanding their physiological functions. Non-invasive techniques to measure cerebral $\mathrm{pH}$ with sufficient spatial and temporal resolution had limited progress. Recently, a magnetic resonance imaging strategy was described that achieved spatial resolution of $\sim 4 \mathrm{~mm}$ and temporal resolution of 6 secs [24]. This technique was able to show that in the human brain (a) breathing $5 \% \mathrm{CO} 2$, consistent with hypercarbic acidosis, produced a widespread decrease in cerebral $\mathrm{pH}$; (b) paced hyperventilation at 27 breaths a minute, consistent with respiratory alkalosis, produced an increase in cerebral $\mathrm{pH}$ [24]. An inference from the above observations is that metabolic acidosis as seen in many people on KDs would be expected to lead to $\mathrm{pH}$ changes in the brain. So, how might limiting systemic acidosis improve seizure control?

The mechanisms by which seizures are terminated are not fully understood. It is likely that multiple mechanisms are involved. One of the mechanisms involved is related to the changes in brain $\mathrm{pH}$. It has been shown that seizures lead to acute acidification of the interstitial fluid, attributed to the production of $\mathrm{CO} 2$ and acid metabolites [25], and recent studies suggest that ASICs may play a significant role in the termination of seizures. ASICs are widely expressed in both the peripheral sensory neurons and CNS neurons. These channels are involved in a variety of physiological and pathological processes such as nociception, mechanosensation, synaptic plasticity and acidosis-mediated neuronal injury. A study in mouse found that disrupting ASIC1a increased the severity of chemoconvulsantinduced seizures, whereas overexpressing ASIC1a had the opposite effect. Overexpressing ASIC1a did not affect seizure threshold or onset, but shortened seizure duration and prevented seizure progression. It is thought that acute acidosis increased neuronal inhibition by activating inhibitory interneurons through ASIC1a. This suggests that ASIC1a may play an important role in seizure termination when brain $\mathrm{pH}$ falls [26]. In another study elevated ASIC3 expression patterns in the brains of people with temporal lobe epilepsy and epileptic rats have been detected. Blocking ASIC3 with an antagonist, shortened the latency to 
seizure and increased the incidence of generalized tonic clonic seizure. These findings suggest that elevated levels of ASIC3 may serve as an anti-epileptic mechanism [27]. While studies have not been conducted, one might speculate that intermittent extracellular acidosis as a consequence of seizure activity might be expected to lead to the observed upregulation of ASIC1a and ASIC3, then chronic systemic metabolic acidosis, i.e. chronic ASIC1a and ASIC3 activation might lead to a down-regulation of these receptors, making this seizure termination mechanism less effective.

The propensity for seizures to occur can be considered to result from the imbalance of excitatory and inhibitory neurotransmission. The principal excitatory input is through the activation of NMDA receptors. It has been suggested [28] that as $\mathrm{H}+$ is a potent inhibitor of NMDA receptor, chronic systemic metabolic acidosis would lead to chronic inhibition of NMDA channels and as a consequence an up-regulation of the channel. The increase in number of NMDA channels makes excitatory neurotransmission more likely to occur, and as a result seizures are more likely. There are clinical observations supporting the suggestion that upregulation of NMDA channels is seizurogenic but no studies of this have been reported. The increase in susceptibility to seizures seen in withdrawal of diazepam [29] and alcohol [30] is thought to be related to the upregulation of NMDA channels.

The reason for suggested opposite effects of acidosis on ASIC1 and NMDA channels is that $\mathrm{H}+$ is an agonist at the ASIC1 channel while it is an inhibitor at NMDA channels. In considering the impact of acidosis on the seizure process, one must also bear in mind the several ways in which acidosis can be produced. As discussed, the occurrence of seizures leads to acidification of the interstitial fluid, and this acidosis may contribute to seizure termination. Other ways of producing acute acidosis such as breathing $5 \% \mathrm{CO} 2$, shown to produce widespread cerebral acidosis as discussed above, produced acute antiseizurogenic effects in rats, monkeys and in humans [31]. Acute acidosis probably exerts antiseizure effects through several mechanisms including activation of ASIC1a channels and inhibiting NMDA receptors as discussed above. Acute acidosis needs to be clearly distinguished from chronic acidosis. Chronic metabolic acidosis can result from dietary factors and KD is particularly potent in producing chronic acidosis as ketone bodies are acidic and other products of lipid metabolism are also acidic. If protein intake becomes excessive, the acidic metabolic products increase the overall systemic burden. KD is also generally deficient in alkaline-forming foods. We argue in this section that chronic acidosis has opposite effects from acute acidosis and is likely to produce greater susceptibility to seizures.

The principal inhibitory neurotransmission involves GABAergic neurons. In a study using murine cortical slices, whole-cell voltage-clamp techniques showed impaired cortical GABAergic neuronal function when the $\mathrm{pH}$ of the perfusate was changed from 7.35 to 6.75 . This procedure was considered to simulate clinical acidosis conditions [32]. Hence, there is the suggestion that chronic acidosis may result in increased excitatory and diminished inhibitory inputs, both favouring the occurrence of seizures. Clearly, more work needs to be undertaken to confirm these potential influences.

Recent studies suggest that inflammation plays a significant role in the pathophysiology of seizures. The experimental and clinical evidence supporting the role of inflammation in seizures has been reviewed by several authors [33-35]. There are now several studies using macrophages documenting the effect of extracellular $\mathrm{pH}$ on the synthesis and release of inflammatory mediators. Studies using $\mathrm{HCl}$ as the acidifying agent consistently show proinflammatory effects at the level of nuclear factor kappa $b$ DNA binding and Tumour 
Necrosis Factor (TNF) synthesis [36]. Hence, limiting the acidosis of dietary treatments for epilepsy may also avoid acidosis-related proinflammatory effects.

A number of drugs are known to produce metabolic acidosis through a number of different renal mechanisms [37] and, in particular, a number of AEDs are carbonic anhydrase inhibitors producing metabolic acidosis by inhibiting the reabsorption of bicarbonate from renal tubules. Hence, it is particularly relevant to limit acidosis in people who are on drugs known to produce metabolic acidosis.

\section{Chronic metabolic acidosis has negative impact on general health}

Research has shown that higher levels of inflammatory biomarkers are associated with the development of a number of diseases including cardiovascular disease [38] and cancer [39], and increase in all-cause mortality [40]. The factors that lead to increase in systemic inflammation have so far not been elucidated. In a cross-sectional study of 4525 healthy adults, lower serum bicarbonate and higher serum anion gap were associated with higher levels of inflammatory markers [41]. Therefore, acidosis may be one of the factors that causes an increase in systemic inflammation. A large population study showed that those with low bicarbonate levels $(<22 \mathrm{mM})$ had a $75 \%$ increased risk of mortality over a mean follow-up period of 8.6 years, compared with the reference group (bicarbonate $26-30 \mathrm{mM}$ ) [42]. In a study of 31,590 adults, those with an acidic urine $(\mathrm{pH} \leq 5.5)$ compared to those with alkaline urine $(\mathrm{pH} \geq 8)$ also had a significantly increased hazard ratio $(2.6,95 \% \mathrm{Cl} 1.3$ 4.9) for all-cause mortality [43].

Acidosis may also have an impact on cardiometabolic risk factors. In a cross sectional study involving 1136 female students, higher estimated dietary acid load was significantly associated with several risk factors including systolic and diastolic blood pressure, LDL cholesterol levels, BMI and waist circumference [44].

The modern Western diet is acidogenic and produces a low-grade metabolic acidosis associated with microalbuminuria, insulin resistance and increased cardiovascular risk [45]. A number of studies suggest metabolic acidosis leads to insulin resistance and increases the risk of developing type 2 diabetes. A study in 16 healthy volunteers showed that the induction of mild metabolic acidosis with ammonium-chloride resulted in a decrease in insulin sensitivity [46]. Conversely, 4 weeks of sodium bicarbonate treatment in people with chronic renal failure reversed metabolic acidosis and led to an increase in insulin sensitivity [47]. A prospective case-controlled study including 630 women who developed type 2 diabetes during a 10 year follow-up, showed that those with plasma sodium bicarbonate greater than the median level had a lower odds ratio (OR $0.76,95 \%$ confidence interval [Cl] 0.60-0.96) of developing diabetes compared with women below the median level.

Additionally, a large prospective study including 66485 women followed up for 14 years showed that higher dietary acid load was associated with an increased incidence in type 2 diabetes [48].

Sodium bicarbonate concentration, a marker for metabolic acidosis, is an established predictor for progression of chronic kidney disease (CKD). But even in subjects with normal eGFR (estimated glomerular filtration rate $>60 \mathrm{~mL} / \mathrm{min} / 1.73 \mathrm{~m}^{2}$ ), low sodium bicarbonate indicative of metabolic acidosis, was associated with a greater risk of development of CKD [49]. 
A number of clinical and preclinical studies have been undertaken to elucidate the role of cerebral $\mathrm{pH}$ in the pathological mechanisms of panic attacks. The studies generally suggest that factors that lead to cerebral acidosis e.g. produced by $\mathrm{CO} 2$ inhalation or lactate infusion, can provoke panic attacks in people with the disorder. Hence disturbance in cerebral $\mathrm{pH}$ homeostasis appears to have a role in panic disorder [50].

In a healthy volunteer study, chronic metabolic acidosis was induced by administering $\mathrm{NH} 4 \mathrm{Cl}$ to six male subjects. Mean plasma bicarbonate concentration decreased significantly from 25.0 to $15.5 \mathrm{mmol} / \mathrm{l}$. The chronic metabolic acidosis produced by this procedure resulted in a decrease in thyroid function [51]. The thyroid hormone is known to have both non-genomic and genomic effects on increasing mitochondrial biogenesis and function [52]. It has been suggested by a number of authors that mitochondrial dysfunction plays a role in the underlying pathophysiology of a wide range of seemingly unrelated medical conditions including cancer, osteoporosis, diabetes, cardiovascular disease, biliary cirrhosis, retinitis pigmentosa, psychiatric disorders, neurodegenerative conditions and epilepsy [53-57].

It is becoming clear that metabolic acidosis produced acutely by administering ammonium chloride or as assessed by high dietary acid load, low serum bicarbonate concentrations, high serum anion gap, and acidic urine, can have a wide ranging and negative impact on many conditions that contribute to general health.

\section{Hypothesis}

Our review clearly suggests that low-grade chronic metabolic acidosis which may complicate the KD is associated with acute and chronic adverse effects. The growing evidence on the potential effects of acidosis on seizurogenic mechanisms suggests that limiting acidosis may improve seizure control. Low-grade chronic metabolic acidosis also appears to have wide ranging negative health consequences. For these reasons, we hypothesize that modifying the $\mathrm{KD}$ to reduce low-grade chronic metabolic acidosis is likely to reduce adverse effects and improve seizure control.

\section{Proposal for an acidosis-sparing ketogenic diet (ASK).}

Even though mechanisms of the antiepileptic effects of KD have not been fully understood, it seems that the potential for the therapeutic effects of KD could be disrupted by low-grade chronic metabolic acidosis. We would like to suggest an acidosis-sparing ketogenic (ASK) diet which evolved to improve the efficacy and tolerability of the classic KD in an adult female subject (see Appendix 1)

The principal elements of the ASK diet comprise:

\subsection{Measures to reduce acidosis.}

\subsubsection{Limit circulating ketone bodies.}

As the ketone bodies are acidic (acetoacetate, pKa 3.6; beta-hydroxybutyrate, pKa 4.7; acetone, pKa 20), and they have not been shown to correlate consistently with efficacy [58], the ASK diet attempts at least initially to avoid high ketone levels, tentatively setting target 
BHB levels of around $2 \mathrm{mM} / \mathrm{L}$ and urine ketones at moderate $(4 \mathrm{mM} / \mathrm{L})$ or lower. The main means to achieve this is to start dietary treatment with $60 \%$ calories from fat. In nonresponsive individuals, a gradual increase to a maximum of $80-90 \%$ calories from fat determining whether a higher systemic acidity might be well tolerated and whether ketogenic ratio up to a $4: 1$ ratio of fat to combined protein and carbohydrate ( $90 \%$ fat) is more therapeutic for the individual.

Intake of the higher amounts of ketogenic medium-chain triglycerides (MCTs) [59] and polyunsaturated fatty acids (PUFA)s [60] is controlled by selecting certain foods with a view to balancing the overall fatty acid profile of the diet.

Caloric intake also affects the degree of ketosis. A factor in achieving moderate ketonemia is avoidance of calorie restriction [61].

\subsubsection{Control protein intake.}

Metabolism of protein generates sulfuric acid and is the major factor in contributing to endogenous acid production in normal Western diets [62]. The ketogenic branched-chain amino acids (BCAAs) in whey products may also increase the production of ketone bodies [63]. However, in order to compensate for loss of nutrients in high fat diet, the recommended dietary allowance (RDA) of $0.8 \mathrm{~g}$ protein per kilogram of body weight is raised, to $\sim 1-1.2 \mathrm{~g} / \mathrm{kg}$ with a view to enhancing nutrition and metabolic functions [64].

6.1.3. Formulate meals with a large, fixed quantity of low-carbohydrate green vegetables.

Potassium and bicarbonate-rich, low-carbohydrate, alkaline-ash producing green vegetables serve to neutralize endogenous acid production [62].

\subsubsection{Include a lemon or lime each day.}

The citrate in lemon or lime is metabolized in the liver to generate bicarbonate.

\subsubsection{Include a magnesium citrate supplement.}

If the above steps are insufficient to neutralize the acidosis and/or constipation is a problem, a magnesium citrate supplement may be necessary. Each molecule of citrate is converted by the liver to 3 molecules of bicarbonate. Magnesium citrate is suggested because magnesium itself may have anti-seizure properties [65-68].

\subsubsection{Avoid, if possible, acid-producing drugs and nutritional supplements.}

A number of drugs are known to affect the body's acid-base balance. Drugs that lead to metabolic acidosis caused by acid load or base loss have been reviewed [69]. AEDs that inhibit carbonic anhydrase may cause metabolic acidosis [70].

\subsection{Composition of the diet}

\subsubsection{Fats}

A large number of traditional ethnic diets in different parts of the world have especially prized the milk fat of ruminants rich in saturated fatty acids which are a major part of the phospholipids (lecithins in all cells) that support the integrity of neural cell membranes. Dairy fat contains: vitamins $A, D, E$ and $K$; cholesterol that is important for myelin synthesis; bioactive fatty acids e.g. butyric acid which lowers inflammation in the intestine; caproic, 
caprylic, capric and lauric acids with anti-microbial, anti-viral, and anti-fungal properties; myristic acid known to raise HDL cholesterol to bind and eliminate toxins, protect cells and lipoproteins from damage, and participates in their repair; stearic acid with beneficial effects on thrombogenic and atherogenic risk factors [71]. The more than 400 fatty acids in dairy fat are complemented with foods providing additional monounsaturates and polyunsaturates: egg yolk, pork, nuts and seeds. In addition, fish provides docosahexaenoic and eicosapentaenoic acids, and beef and lamb provide arachidonic acid. The goal is to mimic, as closely as possible, the fatty acid composition of human milk, which is the unique biological template for the nurture of the human brain. Furthermore, breastfeeding has been linked to decreased epilepsy in childhood [72].

In a diet of $2000 \mathrm{kcal}$, the percentage of energy derived from lipids might be started at 1200 $\mathrm{kcal}(60 \%)$ and might be raised gradually to the classic KD 3 or $4: 1$ ratios of fat to combined protein and carbohydrate by weight.

\subsubsection{Protein}

Protein intake is controlled as discussed above. Protein foods are eggs, a daily staple that boosts nutrition with the fat soluble vitamins $A D E$ and $K$, several $B$ vitamins, minerals including selenium, essential fatty acids, lecithin and cholesterol. Beef and lamb are staples high in carnitine to support the beta-oxidation of fatty acids [73], and carnosine known to function as an acid-base buffer [74]. Pork is also a staple that is known to increase monounsaturated fatty acids (MUFA) and thiamine. It has been suggested that thiamine deficiency may provoke seizures [75].

\subsubsection{Carbohydrate}

Carbohydrate is anti-ketogenic. Hence, starches and sugars are not allowed. Carbohydrates from green leafy vegetables and other vegetables with low carbohydrate content are allowed and constitute the main bulk of each meal. In addition, carbohydrates in lemon, lime, the fatty fruits avocado and olive are allowed, as well as nuts and seeds which contribute to important nutritional and metabolic effects. Inclusion of artisanal fermented vegetables like sauerkraut and kimchee may improve the gut microbiome and stimulate the vagal afferents to the brain. It has been suggested that stimulating the vagus nerve may help to improve seizure control [76]. Since a number of chemicals used in food production and processing have been shown to be mitochondrial inhibitors and have widespread negative effects on cellular metabolism [77], fresh, local, organically grown produce is preferred.

The high volume of green vegetables recommended for their generous alkaline mineral content provide only approximately $30 \mathrm{~g} / \mathrm{d}$ carbohydrate. The estimated initial ketogenic ratio is approximately $2: 1$.

\subsubsection{Hydration}

Steady maintenance of hydration, neither too much fluid nor too little, is of the utmost importance, hence testing the urine for specific gravity is recommended at times when the prescribed daily fluid intake may be compromised. Mineral waters rich in bicarbonate, magnesium, and calcium, low in sodium, and without fluoride are preferred.

\subsection{Other important elements of the diet:}


The high ATP levels resulting from a KD may be involved in helping normalize synaptic transmission [78], and nutrients in dietary substrate may also affect neurotransmission [79]. Hence, specific nutrient-dense foods are prescribed as staples most likely to support metabolic and nutritional needs. Furthermore, environmental toxins [80] and drugs [80, 81], including AEDs [82] that inhibit mitochondrial function, are avoided as much as possible.

A case history of a subject using the ASK diet is given in Appendix 1 and details of her meal plan is given in Appendix 2.

\section{Discussion}

Two randomized clinical trials have demonstrated the efficacy of the classic ketogenic diet $[83,84]$, and the positive experience in using the classic KD and its variants in childhood epilepsy have been reviewed $[85,86]$. There is also now increasing experience with the use of the classic KD and its variants in adults $[87,88]$. As with pharmacological therapies, a significant proportion of people do not respond to KD. Approximately half of people tried on KD do not show a greater than $50 \%$ seizure reduction. There are also issues of acceptability of the diet and there can be significant adverse effects. Acidosis and uncertainties of nutritional management complicate clinical management and discourage use of ketogenic dietary treatment. We raise the question of whether changes to KD might improve efficacy and reduce potential adverse effects. In this paper we suggest that controlling the potential low-grade chronic acidosis and supporting metabolic regulation by prescribing specific, nutrient-dense whole foods may be important strategies to improve efficacy and tolerance. Clearly clinical research is required to determine if indeed avoiding acidosis and enhancing nutrition can improve KD efficacy and tolerability.

\section{Future studies}

Initially open studies should be conducted to verify that indeed the ASK diet can avoid lowgrade chronic metabolic acidosis as assessed by serum anion gap and bicarbonate levels. The studies should also determine if efficacy is improved or at least not compromised by the changes to avoid acidosis. These studies should also determine the best strategies in initiating the diet and to verify if indeed acute side effects are avoided with the ASK diet. If efficacy is not optimal, the studies should determine if higher levels of ketones provide better seizure control and if those levels are still well tolerated and are not producing low-grade chronic metabolic acidosis. Following the greater experience in using the ASK diet in open studies, comparative studies with the classical KD and other KD variants should be undertaken to ascertain if the hypothesis can be confirmed.

Conflicts of interest: None declared.

Acknowledgement: We thank Dr Ghazala Mirza for her helpful comments on the article.

This research did not receive any specific grant from funding agencies in the public, commercial, or not-for-profit sectors. 


\section{Appendix 1}

A case history (Presented at the Global Symposium on the Dietary Treatments of Epilepsy and Other Neurological Disorders, Edinburgh, 2010.)

$\mathrm{RA}$ is a $41 \mathrm{yr}$. old female with subcortical band heterotopia. She had autism and seizures with multiple atypical seizure types which started when she was 9 months old. She was first hospitalized for status epilepticus (SE) at age 13. Her seizures remained refractory on various AED combinations. She had 8 further admissions because of SE, the last SE and hospitalization occurring at age 33. RA started ketogenic dietary treatment at age 27 . Her dietary management has evolved over a period of 14 years. Her ketogenic diet has been modified for improved nutritional support, reduction of metabolic acidosis, avoidance of neurotoxins, and protection of mitochondrial and peroxisomal beta-oxidation pathways. Since age 33 years RA has been without overt episode of seizure of either a clearly defined complex partial or secondary generalized nature. EEG at age 35 was essentially normal. Primary treatment consists of phenytoin, maintained at maximum therapeutic level, high dose levetiracetam, and ketogenic-based diet ( 80 to $90 \%$ calories from fat). RA is now in excellent health, and shows cognitive and social rehabilitation indicative of recovery from autistic dysfunction. RA's physical examination and biochemistry results are given in Table 1 and RA's most recent meal plan is given in Appendix 2. 
Table 1. Physical Exam and Biochemistry Results

\begin{tabular}{|c|c|c|}
\hline PHYSICAL EXAM & & \\
\hline Weight & $56.6 \mathrm{~kg}$ & \\
\hline Height & $159 \mathrm{~cm}$ & \\
\hline Blood pressure & $120 / 81 \mathrm{~mm} / \mathrm{Hg}$ & \\
\hline Pulse & 83 beats/min & \\
\hline Neurological exam & $\begin{array}{l}\text { Unremarkable, except for } \\
\text { inappropriate behaviors }\end{array}$ & \\
\hline BIOCHEMISTRY & & Normal range \\
\hline Sodium & $136 \mathrm{mEq} / \mathrm{L}$ & $135-145$ \\
\hline Potassium & $4.1 \mathrm{mEq} / \mathrm{L}$ & $3.5-5.2$ \\
\hline Chloride & $103 \mathrm{mEq} / \mathrm{L}$ & $95-109$ \\
\hline CO2 Content & $25 \mathrm{mEq} / \mathrm{L}$ & $22-31$ \\
\hline Glucose & 77 mg/dL $(4.3 \mathrm{mmol} / \mathrm{L})$ & $70-99$ \\
\hline Creatinine & $0.7 \mathrm{mg} / \mathrm{dL}$ (61umol/L) & $0.6-1.1$ \\
\hline Calcium & $9.7 \mathrm{mg} / \mathrm{dL}(2.4 \mathrm{mmol} / \mathrm{L})$ & $8.6-10.2$ \\
\hline \multicolumn{3}{|l|}{ Lipids } \\
\hline HDL & $82 \mathrm{mg} / \mathrm{dL} \quad(2.1 \mathrm{mmol} / \mathrm{L})$ & $>59$ low risk \\
\hline LDL & $156 \mathrm{mg} / \mathrm{dL} \quad(4.0 \mathrm{mmol} / \mathrm{L})$ & $130-159$ borderline \\
\hline Cholesterol & $250 \mathrm{mg} / \mathrm{dL}(6.5 \mathrm{mmol} / \mathrm{L})$ & $>239$ high \\
\hline Triglycerides & $59 \mathrm{mg} / \mathrm{dL} \quad(0.7 \mathrm{mmol} / \mathrm{L})$ & $<150$ normal \\
\hline $\mathrm{CHO} / \mathrm{HDL}$ ratio & 3.0 & $<5$ desirable \\
\hline Carnitine, free & $37 \mathrm{umol} / \mathrm{L}$ & $25-60$ \\
\hline Beta-hydroxybutyrate & $3.3 \mathrm{mg} / \mathrm{dL} \quad(0.3 \mathrm{mmol} / \mathrm{L})$ & $0-3.0$ \\
\hline Ketones (not BHB) & Negative & Negative \\
\hline
\end{tabular}




\section{Appendix 2}

RA's Meal Plan (2012-2016)

The plan below accommodated RA's energy requirement with $\sim 80 \%$ calories from fat. Preparation of her meals was on stove-top at low heat. Ingredients were mixed together to form an approximately isocaloric homogeneous meal, with raw ingredients incorporated upon serving. 


\begin{tabular}{|c|c|c|}
\hline Breakfast & Lunch & Dinner \\
\hline $\begin{array}{l}2 \text { free-range eggs; } 2 \text { TBSP } \\
\text { clarified butter (ghee); } 2 \text { TBSP } \\
\text { whipping cream }\end{array}$ & $\begin{array}{l}\text { Rotation of 3oz pastured beef, } \\
\text { lamb, pork; } 2 \text { TBSP ghee }\end{array}$ & $\begin{array}{l}3 \text { oz cold water fish; } 2 \text { TBSP } \\
\text { crème fraîche }\end{array}$ \\
\hline $\begin{array}{l}1 \text { cup cooked fresh, organic } \\
\text { vegetables } \\
\text { (choose } 3 \text { ) }\end{array}$ & $\begin{array}{l}1 \text { cup cooked fresh, organic } \\
\text { vegetables } \\
\text { (choose } 3 \text { ) }\end{array}$ & $\begin{array}{l}1 \text { cup cooked fresh, organic } \\
\text { vegetables } \\
\text { (choose } 3 \text { ) }\end{array}$ \\
\hline $\begin{array}{l}1 \text { cup uncooked vegetables } \\
\text { (choose } 3 \text { ) }\end{array}$ & $\begin{array}{l}1 \text { cup uncooked vegetables } \\
\text { (choose } 3 \text { ) }\end{array}$ & $\begin{array}{l}1 \text { cup uncooked vegetables } \\
\text { (choose } 3 \text { ) }\end{array}$ \\
\hline 1/3 lemon (juice and pulp) & 1/3 lemon (juice and pulp) & 1/3 lemon (juice and pulp) \\
\hline $\begin{array}{l}2 \text { tsp sea salt, sesame seeds, } \\
\text { seaweed condiment (gomasio) }\end{array}$ & 2 tsp seaweed gomasio & 2 tsp seaweed gomasio \\
\hline 1 walnut; 2 almonds & 1 walnut; 2 almonds & 1 walnut; 2 almonds \\
\hline $\begin{array}{l}\text { Beverage - approved herbal } \\
\text { tea; } 2 \text { TBSP whipping cream } \\
\text { In addition to the breakfast } \\
\text { beverage, a mid-morning } \\
\text { beverage may be required to } \\
\text { fulfill the required fluid intake. }\end{array}$ & $\begin{array}{l}\text { Beverage - approved herbal } \\
\text { tea; } 2 \text { TBSP whipping cream } \\
\text { In addition to the lunch } \\
\text { beverage, a mid-afternoon } \\
\text { beverage may be required to } \\
\text { fulfill the required fluid intake. }\end{array}$ & $\begin{array}{l}\text { Beverage - approved herbal } \\
\text { tea; } 2 \text { TBSP whipping cream } \\
\text { In addition to the dinner } \\
\text { beverage, a bed-time } \\
\text { beverage may be required to } \\
\text { fulfill the required fluid intake. }\end{array}$ \\
\hline
\end{tabular}

Cooked Fresh Organic Vegetables: alfalfa/bean sprouts, artichokes, asparagus, bamboo shoots, beet greens, bok choy, broccoli, broccolini, Brussels sprouts, cabbage, cauliflower, celery, chard, collard greens, eggplant, green beans (haricots), green bell peppers, green onions (scallions), kale, kohlrabi, leeks, mustard greens, okra, pumpkin, snap peas, snow peas, spinach, swiss chard, turnips, water chestnuts, zucchini squash (courgette). Chives, cilantro, curry spices, marjoram, oregano, parsley, and thyme may be included in cooking.

Uncooked Fresh Organic Vegetables: arugula (roquette), avocado, bamboo shoots, basil, celery, cilantro, cucumber, daikon radish, escarole, endive, green onions (scallions), green bell peppers, jicama, kohlrabi, lettuce (all varieties and mixed salad greens), parsley, salt- 
fermented vegetables (sauerkraut, pickled cabbage (kimchee), pickles), seaweeds (sea vegetables), water chestnuts, watercress.

Beverages: mineral and spring waters high in calcium and bicarbonates and without fluoride; hot and cold infusions of mint, holy basil (tulsi) tea, passionfruit, ginger, lemon, coconut cream, with cinnamon or pure vanilla essence; cream "shakes"/"smoothies"; meat broths and soups; vegetable juices and soups. 


\section{Reference List}

[1] Kelly MT, Hays TL. Implementing the ketogenic diet. Top Clin Nutr 1997;13:53-61.

[2] Wheless JW. History of the ketogenic diet. Epilepsia 2008;49 Suppl 8:3-5.

[3] Brodie MJ. Road to refractory epilepsy: the Glasgow story. Epilepsia 2013;54 Suppl 2:5-8.

[4] Pizzorno J, Frassetto LA, Katzinger J. Diet-induced acidosis: is it real and clinically relevant? $\mathrm{Br}$ J Nutr 2010;103:1185-94.

[5] Millichap JG, Jones JD. Acid-base, electrolyte, and amino-acid metabolism in childrenwith petit mal. Etiologic significance and modification by anticonvulsant drugs and the ketogenic diet. Epilepsia 1964;5:239-55.

[6] Takeoka M, Riviello JJ, Jr., Pfeifer H, Thiele EA. Concomitant treatment with topiramate and ketogenic diet in pediatric epilepsy. Epilepsia 2002;43:1072-5.

[7] Yancy WS, Jr., Olsen MK, Dudley T, Westman EC. Acid-base analysis of individuals following two weight loss diets. Eur J Clin Nutr 2007;61:1416-22.

[8] Kang HC, Chung DE, Kim DW, Kim HD. Early- and late-onset complications of the ketogenic diet for intractable epilepsy. Epilepsia 2004;45:1116-23.

[9] Melamed P, Melamed F. Chronic metabolic acidosis destroys pancreas. JOP 2014;15:552-60.

[10] McNally MA, Pyzik PL, Rubenstein JE, Hamdy RF, Kossoff EH. Empiric use of potassium citrate reduces kidney-stone incidence with the ketogenic diet. Pediatrics 2009;124:e300-e304.

[11] Hahn TJ, Halstead LR, DeVivo DC. Disordered mineral metabolism produced by ketogenic diet therapy. Calcif Tissue Int 1979;28:17-22.

[12] Bergqvist AG, Schall JI, Stallings VA, Zemel BS. Progressive bone mineral content loss in children with intractable epilepsy treated with the ketogenic diet. Am J Clin Nutr 2008;88:1678-84.

[13] Arnett TR. Extracellular pH regulates bone cell function. J Nutr 2008;138:415S-8S.

[14] Adeva MM, Souto G. Diet-induced metabolic acidosis. Clin Nutr 2011;30:416-21.

[15] Chen W, Melamed ML, Abramowitz MK. Serum bicarbonate and bone mineral density in US adults. Am J Kidney Dis 2015;65:240-8.

[16] Groesbeck DK, Bluml RM, Kossoff EH. Long-term use of the ketogenic diet in the treatment of epilepsy. Dev Med Child Neurol 2006;48:978-81. 
[17] Vining EP, Pyzik P, McGrogan J, Hladky H, Anand A, Kriegler S et al. Growth of children on the ketogenic diet. Dev Med Child Neurol 2002;44:796-802.

[18] Williams S, Basualdo-Hammond C, Curtis R, Schuller R. Growth retardation in children with epilepsy on the ketogenic diet: a retrospective chart review. J Am Diet Assoc 2002;102:4057.

[19] Hsu SY, Tsai IJ, Tsau YK. Comparison of growth in primary Fanconi syndrome and proximal renal tubular acidosis. Pediatr Nephrol 2005;20:460-4.

[20] de-Brito Ashurst I, O'Lone E, Kaushik T, McCafferty K, Yaqoob MM. Acidosis: progression of chronic kidney disease and quality of life. Pediatr Nephrol 2015;30:873-9.

[21] Best TH, Franz DN, Gilbert DL, Nelson DP, Epstein MR. Cardiac complications in pediatric patients on the ketogenic diet. Neurology 2000;54:2328-30.

[22] Krishtal OA, Pidoplichko VI. Receptor for protons in the membrane of sensory neurons. Brain Res 1981;214:150-4.

[23] Waldmann R, Champigny G, Bassilana F, Heurteaux C, Lazdunski M. A proton-gated cation channel involved in acid-sensing. Nature 1997;386:173-7.

[24] Magnotta VA, Heo HY, Dlouhy BJ, Dahdaleh NS, Follmer RL, Thedens DR et al. Detecting activity-evoked pH changes in human brain. Proc Natl Acad Sci U S A 2012;109:8270-3.

[25] Somjen GG. Acidification of interstitial fluid in hippocampal formation caused by seizures and by spreading depression. Brain Res 1984;311:186-8.

[26] Ziemann AE, Schnizler MK, Albert GW, Severson MA, Howard MA, III, Welsh MJ et al. Seizure termination by acidosis depends on ASIC1a. Nat Neurosci 2008;11:816-22.

[27] Cao Q, Wang W, Gu J, Jiang G, Wang K, Xu Z et al. Elevated Expression of Acid-Sensing Ion Channel 3 Inhibits Epilepsy via Activation of Interneurons. Mol Neurobiol 2014.

[28] Yuen AW. Low-grade chronic metabolic acidosis is a contributory mechanism in the development of chronic epilepsy. Epilepsy Behav 2006;8:347-9.

[29] Tsuda M, Shimizu N, Yajima Y, Suzuki T, Misawa M. Hypersusceptibility to DMCM-induced seizures during diazepam withdrawal in mice: evidence for upregulation of NMDA receptors. Naunyn Schmiedebergs Arch Pharmacol 1998;357:309-15.

[30] Tsai G, Coyle JT. The role of glutamatergic neurotransmission in the pathophysiology of alcoholism. Annu Rev Med 1998;49:173-84.

[31] Miller JW. Stopping seizures with carbon dioxide. Epilepsy Curr 2011;11:114-5.

[32] Li F, Liu X, Su Z, Sun R. Acidosis leads to brain dysfunctions through impairing cortical GABAergic neurons. Biochem Biophys Res Commun 2011;410:775-9.

[33] Vezzani A. Epilepsy and inflammation in the brain: overview and pathophysiology. Epilepsy Curr 2014;14:3-7. 
[34] Dupuis N, Auvin S. Inflammation and epilepsy in the developing brain: clinical and experimental evidence. CNS Neurosci Ther 2015;21:141-51.

[35] Shimada T, Takemiya T, Sugiura H, Yamagata K. Role of inflammatory mediators in the pathogenesis of epilepsy. Mediators Inflamm 2014;2014:901902.

[36] Kellum JA, Song M, Li J. Science review: extracellular acidosis and the immune response: clinical and physiologic implications. Crit Care 2004;8:331-6.

[37] Liamis G, Milionis HJ, Elisaf M. Pharmacologically-induced metabolic acidosis: a review. Drug Saf 2010;33:371-91.

[38] Ridker PM, Cushman M, Stampfer MJ, Tracy RP, Hennekens CH. Inflammation, aspirin, and the risk of cardiovascular disease in apparently healthy men. N Engl J Med 1997;336:973-9.

[39] Erlinger TP, Muntner P, Helzlsouer KJ. WBC count and the risk of cancer mortality in a national sample of U.S. adults: results from the Second National Health and Nutrition Examination Survey mortality study. Cancer Epidemiol Biomarkers Prev 2004;13:1052-6.

[40] Ruggiero C, Metter EJ, Cherubini A, Maggio M, Sen R, Najjar SS et al. White blood cell count and mortality in the Baltimore Longitudinal Study of Aging. J Am Coll Cardiol 2007;49:184150 .

[41] Farwell WR, Taylor EN. Serum anion gap, bicarbonate and biomarkers of inflammation in healthy individuals in a national survey. CMAJ 2010;182:137-41.

[42] Raphael KL, Zhang Y, Wei G, Greene T, Cheung AK, Beddhu S. Serum bicarbonate and mortality in adults in NHANES III. Nephrol Dial Transplant 2013;28:1207-13.

[43] Park M, Jung SJ, Yoon S, Yun JM, Yoon HJ. Association between the markers of metabolic acid load and higher all-cause and cardiovascular mortality in a general population with preserved renal function. Hypertens Res 2015;38:433-8.

[44] Murakami K, Sasaki S, Takahashi Y, Uenishi K. Association between dietary acid-base load and cardiometabolic risk factors in young Japanese women. Br J Nutr 2008;100:642-51.

[45] Souto G, Donapetry C, Calvino J, Adeva MM. Metabolic acidosis-induced insulin resistance and cardiovascular risk. Metab Syndr Relat Disord 2011;9:247-53.

[46] DeFronzo RA, Beckles AD. Glucose intolerance following chronic metabolic acidosis in man. Am J Physiol 1979;236:E328-E334.

[47] Reaich D, Graham KA, Channon SM, Hetherington C, Scrimgeour CM, Wilkinson R et al. Insulin-mediated changes in PD and glucose uptake after correction of acidosis in humans with CRF. Am J Physiol 1995;268:E121-E126.

[48] Fagherazzi G, Vilier A, Bonnet F, Lajous M, Balkau B, Boutron-Rualt MC et al. Dietary acid load and risk of type 2 diabetes: the E3N-EPIC cohort study. Diabetologia 2014;57:313-20.

[49] Driver TH, Shlipak MG, Katz R, Goldenstein L, Sarnak MJ, Hoofnagle AN et al. Low serum bicarbonate and kidney function decline: the Multi-Ethnic Study of Atherosclerosis (MESA). Am J Kidney Dis 2014;64:534-41. 
[50] Vollmer LL, Strawn JR, Sah R. Acid-base dysregulation and chemosensory mechanisms in panic disorder: a translational update. Transl Psychiatry 2015;5:e572.

[51] Brungger M, Hulter HN, Krapf R. Effect of chronic metabolic acidosis on thyroid hormone homeostasis in humans. Am J Physiol 1997;272:F648-F653.

[52] Weitzel JM, Iwen KA. Coordination of mitochondrial biogenesis by thyroid hormone. Mol Cell Endocrinol 2011;342:1-7.

[53] Boland ML, Chourasia AH, Macleod KF. Mitochondrial dysfunction in cancer. Front Oncol 2013;3:292.

[54] Lane RK, Hilsabeck T, Rea SL. The role of mitochondrial dysfunction in age-related diseases. Biochim Biophys Acta 2015;1847:1387-400.

[55] Montgomery MK, Turner N. Mitochondrial dysfunction and insulin resistance: an update. Endocr Connect 2015;4:R1-R15.

[56] Pieczenik SR, Neustadt J. Mitochondrial dysfunction and molecular pathways of disease. Exp Mol Pathol 2007;83:84-92.

[57] Yuen AW, Sander JW. Impaired mitochondrial energy production: the basis of pharmacoresistance in epilepsy. Med Hypotheses 2011;77:536-40.

[58] Schoeler NE, Cross JH, Sander JW, Sisodiya SM. Can we predict a favourable response to Ketogenic Diet Therapies for drug-resistant epilepsy? Epilepsy Res 2013;106:1-16.

[59] Likhodii SS, Musa K, Mendonca A, Dell C, Burnham WM, Cunnane SC. Dietary fat, ketosis, and seizure resistance in rats on the ketogenic diet. Epilepsia 2000;41:1400-10.

[60] Cunnane SC. Metabolism of polyunsaturated fatty acids and ketogenesis: an emerging connection. Prostaglandins Leukot Essent Fatty Acids 2004;70:237-41.

[61] Eagles DA, Boyd SJ, Kotak A, Allan F. Calorie restriction of a high-carbohydrate diet elevates the threshold of PTZ-induced seizures to values equal to those seen with a ketogenic diet. Epilepsy Res 2003;54:41-52.

[62] Frassetto LA, Todd KM, Morris RC, Jr., Sebastian A. Estimation of net endogenous noncarbonic acid production in humans from diet potassium and protein contents. Am J Clin Nutr 1998;68:576-83.

[63] Evangeliou A, Spilioti M, Doulioglou V, Kalaidopoulou P, Ilias A, Skarpalezou A et al. Branched chain amino acids as adjunctive therapy to ketogenic diet in epilepsy: pilot study and hypothesis. J Child Neurol 2009;24:1268-72.

[64] Layman DK, Anthony TG, Rasmussen BB, Adams SH, Lynch CJ, Brinkworth GD et al. Defining meal requirements for protein to optimize metabolic roles of amino acids. Am J Clin Nutr 2015.

[65] Yuen AW, Sander JW. Can magnesium supplementation reduce seizures in people with epilepsy? A hypothesis. Epilepsy Res 2012;100:152-6. 
[66] Osborn KE, Shytle RD, Frontera AT, Soble JR, Schoenberg MR. Addressing potential role of magnesium dyshomeostasis to improve treatment efficacy for epilepsy: A reexamination of the literature. J Clin Pharmacol 2015.

[67] Abdelmalik PA, Politzer N, Carlen PL. Magnesium as an effective adjunct therapy for drug resistant seizures. Can J Neurol Sci 2012;39:323-7.

[68] Zou LP, Wang X, Dong CH, Chen CH, Zhao W, Zhao RY. Three-week combination treatment with ACTH + magnesium sulfate versus ACTH monotherapy for infantile spasms: a 24-week, randomized, open-label, follow-up study in China. Clin Ther 2010;32:692-700.

[69] Kitterer D, Schwab M, Alscher MD, Braun N, Latus J. Drug-induced acid-base disorders. Pediatr Nephrol 2015;30:1407-23.

[70] Sheth RD. Metabolic concerns associated with antiepileptic medications. Neurology 2004;63:S24-S29.

[71] German JB, Dillard CJ. Saturated fats: a perspective from lactation and milk composition. Lipids 2010;45:915-23.

[72] Sun Y, Vestergaard M, Christensen J, Olsen J. Breastfeeding and risk of epilepsy in childhood: a birth cohort study. J Pediatr 2011;158:924-9.

[73] Pekala J, Patkowska-Sokola B, Bodkowski R, Jamroz D, Nowakowski P, Lochynski S et al. Lcarnitine--metabolic functions and meaning in humans life. Curr Drug Metab 2011;12:66778.

[74] Purchas RW, Rutherfurd SM, Pearce PD, Vather R, Wilkinson BH. Concentrations in beef and lamb of taurine, carnosine, coenzyme Q(10), and creatine. Meat Sci 2004;66:629-37.

[75] Keyser A, De Bruijn SF. Epileptic manifestations and vitamin B1 deficiency. Eur Neurol 1991;31:121-5.

[76] Yuen AW, Sander JW. Can natural ways to stimulate the vagus nerve improve seizure control? Epilepsy Behav 2017;67:105-10.

[77] Karami-Mohajeri S, Abdollahi M. Toxic influence of organophosphate, carbamate, and organochlorine pesticides on cellular metabolism of lipids, proteins, and carbohydrates: a systematic review. Hum Exp Toxicol 2011;30:1119-40.

[78] Masino SA, Kawamura M, Wasser CD, Pomeroy LT, Ruskin DN. Adenosine, ketogenic diet and epilepsy: the emerging therapeutic relationship between metabolism and brain activity. Curr Neuropharmacol 2009;7:257-68.

[79] Wurtman RJ. Synapse formation and cognitive brain development: effect of docosahexaenoic acid and other dietary constituents. Metabolism 2008;57 Suppl 2:S6-10.

[80] Meyer JN, Leung MC, Rooney JP, Sendoel A, Hengartner MO, Kisby GE et al. Mitochondria as a target of environmental toxicants. Toxicol Sci 2013;134:1-17.

[81] Finsterer J, Segall L. Drugs interfering with mitochondrial disorders. Drug Chem Toxicol 2010;33:138-51. 
[82] Finsterer J, Zarrouk MS. Mitochondrial toxicity of antiepileptic drugs and their tolerability in mitochondrial disorders. Expert Opin Drug Metab Toxicol 2012;8:71-9.

[83] Neal EG, Chaffe H, Schwartz RH, Lawson MS, Edwards N, Fitzsimmons G et al. The ketogenic diet for the treatment of childhood epilepsy: a randomised controlled trial. Lancet Neurol 2008;7:500-6.

[84] Lambrechts DA, de Kinderen RJ, Vles JS, de Louw AJ, Aldenkamp AP, Majoie HJ. A randomized controlled trial of the ketogenic diet in refractory childhood epilepsy. Acta Neurol Scand 2016.

[85] Winesett SP, Bessone SK, Kossoff EH. The ketogenic diet in pharmacoresistant childhood epilepsy. Expert Rev Neurother 2015;15:621-8.

[86] Auvin S. Non-pharmacological medical treatment in pediatric epilepsies. Rev Neurol (Paris) 2016;172:182-5.

[87] Ye F, Li XJ, Jiang WL, Sun HB, Liu J. Efficacy of and patient compliance with a ketogenic diet in adults with intractable epilepsy: a meta-analysis. J Clin Neurol 2015;11:26-31.

[88] Cervenka MC, Henry BJ, Felton EA, Patton K, Kossoff EH. Establishing an Adult Epilepsy Diet Center: Experience, efficacy and challenges. Epilepsy Behav 2016;58:61-8. 